\title{
EDITORIAL
}

\section{MANEJO DE VIDA DE UNA ENFERMERA EN LA ERA COVID}

\author{
J. Javier Soldevilla Agreda \\ Director GNEAUPP
}

Muchos meses, mucha tinta, muchas horas de debate, superficial o profundo, demasiados días de información formal poco creíble, de hastío, de desesperanza, de miedo, de duelo, de pena, de visibilidad de las miserias, que siempre, como las riadas, sacan a superficie sistemas sanitarios que eran más fachada que edificio, atención sociosanitaria sustentada en un organigrama nunca cumplido, con orientaciones falsamente filantrópicas que dejaron al descubierto desabastecimiento en la atención, cortinas cerradas que ocultaban una desconocida y fría realidad como el tamaño de manifiestas actitudes gerontofóbicas que han convivido en los peores días... pero hoy quería, con vuestro permiso, recalar en un autoanálisis de lo que en la esfera más íntima de nuestras vidas ha taladrado esta era. Enfermeras dedicadas a la atención de los más mayores o de las heridas o de otros, que en un ańo "dedicado" y finalmente concluso hemos grabado a fuego una experiencia hasta la fecha no vivida, una prueba de resistencia a nuestros cimientos personales y profesionales, pero que tenemos que seguir reforzando, porque lamentablemente esta pandemia no ha terminado; a días sentimos cierta tregua, pero "los malignos" siguen ahí y necesitamos cuidarnos para cuidar.

Permitidme esta licencia navideña para compartir, desde el seno más profundo y herido, un decálogo que nos ayude a protegernos, a seguir afianzando un recetario de valores y atributos que nos permita seguir creciendo en la adversidad como personas, a fortalecer nuestra hechura enfermera. Un ejercicio poco literario, sin armonía ni orden, espontáneo, que, como esas reglas de oro frente a la propagación de la COVID-19, Manos-Metros-Mascarillas, también me propongo que empiece por M.

Mis disculpas si alguien considera una ñońez el ejercicio de hoy en esta tribuna científica, pero no encontraba un regalo mejor en este final del 2020, en este comienzo de un Nuevo Año, que tantas cosas ha puesto al descubierto.

Movilízate frente a las injusticias vistas o vividas con nuestros mayores y heridos.

Muestra lo que hemos aprendido de un tiempo de asedio profesional y aislamiento personal. Comparte y difunde las experiencias para aprender juntos. Vuelve a permitir, como válvula de escape, que renazca tu interés científico y personal por algo más que el coronavirus.

Mujer, madre... marido. Primer mandamiento. Sé todo ello. Reparte con equilibrio ese tiempo, aunque las demandas te parezcan que no son homogéneas.

Marcha. Actívate. En lo físico y en lo intelectual. No permitas que el mundo se detenga.

Madura con esta situación. Sé prudente y juiciosa, pero demuestra...
Maestría como arte o destreza de enseñar o ejecutar una cosa (Enfermería, Ciencia y Arte) y...

Magia, como hechizo o atractivo en tu quehacer de cuidados y cada día con tu familia. Sé...

Magnánima, que habla de grandeza de ánimo.

Malabarista, en el arte diestro para conducir situaciones complicadas en el día a día...

Maleable pero no mamarracha. Entrena tu carácter. No seas arisca ni aproveches en momentos, situaciones de poder. Recuerda que manejas un...

Maná, como manjar milagroso que cada día repartes a tus pacientes. Recuerda que es gratuito y muy nutritivo. La palabra o el silencio. Tampoco olvides llevar de este a casa y repartir con los tuyos.

Mancomuna fuerzas para que puedas repartirlas entre tu profesión, tu familia y tú misma. Practica...

Maneras, porte, modales. Es tu sello distintivo. No dudes en dar a todos...

Mimos como expresión directa de cariño. Romper el caos estructural a la ternura que se nos ha impuesto, con el no tocar, a través de repetidos gestos. No te importe sentir...

Miedo, pero busca racionalmente ese antídoto para aliviar la angustia que provoca el dańo real o imaginario. Requiere entrenar su control. Llora y teme, que es lo normal. Luego enjuga tus lágrimas y maquíllate de positividad. Eres...

Modelo y punto de referencia, aplaudido o no. Abandona, si en algún momento aflora esa...

Modorra que te impide seguir viviendo y viendo un espacio de esperanza. Sueña con él.

Monda lo superfluo y quédate con todo lo importante para ti. No te sientas mal por pensar en ti durante ratos. Sé también una heroína solidaria de puertas adentro.

Manumite a la obligación asfixiante del permanente servicio. Responsabilízate de lo que tú haces, pero no eches sobre tus hombros todo lo que no tienes posibilidades de abarcar o cambiar.

Moraliza, reformando malas costumbres allí donde estés, tendrás una gran recompensa como ser humano y enfermera, aunque no será sencillo.

Muestra sin rubor cómo amas más que nunca a los que tienes y trata de despedirte de aquellos de los que no lo has hecho. Vive también este...

Momento. Nunca se volverá a repetir y tratemos de aprender de él.

De corazón, Feliz Año Nuevo.

Con todo mi carińo 